\title{
Metal-Organic Framework Materials with Ultrahigh Surface Areas: Is the Sky the Limit?
}

Omar K. Farha, ${ }^{*},+$, Ibrahim Eryazici, $^{\dagger, \ddagger}$ Nak Cheon Jeong, ${ }^{\dagger, \perp}$ Brad G. Hauser, ${ }^{\dagger}$ Christopher E. Wilmer, ${ }^{\S}$ Amy A. Sarjeant, ${ }^{\dagger}$ Randall Q. Snurr, ${ }^{\S}$ SonBinh T. Nguyen, ${ }^{\dagger}$ A. Özgür Yazaydın, ${ }^{*, l}$ and Joseph T. Hupp ${ }^{*} \dagger$

${ }^{\dagger}$ Department of Chemistry and International Institute for Nanotechnology, Northwestern University, 2145 Sheridan Road, Evanston, Illinois 60208-3113, United States

${ }^{\S}$ Department of Chemical \& Biological Engineering, Northwestern University, 2145 Sheridan Road, Evanston, Illinois 60208, United States

"Department of Chemical Engineering, University of Surrey, Guildford, GU2 7XH, United Kingdom

${ }^{\perp}$ Department of Emerging Materials Science, Daegu Gyeongbuk Institute of Science and Technology (DGIST), Daegu 711-873, Korea

Supporting Information

ABSTRACT: We have synthesized, characterized, and computationally simulated/validated the behavior of two new metal-organic framework (MOF) materials displaying the highest experimental Brunauer-Emmett-Teller (BET) surface areas of any porous materials reported to date $\left(\sim 7000 \mathrm{~m}^{2} / \mathrm{g}\right)$. Key to evacuating the initially solvent-filled materials without pore collapse, and thereby accessing the ultrahigh areas, is the use of a supercritical $\mathrm{CO}_{2}$ activation technique. Additionally, we demonstrate computationally that by shifting from phenyl groups to "space efficient" acetylene moieties as linker expansion units, the hypothetical maximum surface
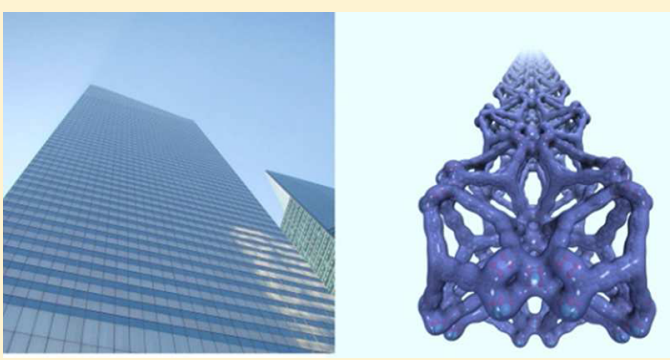
area for a MOF material is substantially greater than previously envisioned $\left(\sim 14600 \mathrm{~m}^{2} / \mathrm{g}\right.$ (or greater) versus $\sim 10500 \mathrm{~m}^{2} / \mathrm{g}$ ).

\section{INTRODUCTION}

Extensive research over the past few years has been focused on the synthesis and characterization of microporous materials with high internal surface areas. Metal-organic frameworks (MOFs) ${ }^{1-3}$ a crystalline subset of these materials, have shown promise in a wide range of applications from gas storage, ${ }^{4-6}$ chemical separations, ${ }^{7-10}$ chemical sensing, ${ }^{11}$ and catalysis, ${ }^{12-14}$ to ion exchange, ${ }^{15}$ light harvesting, ${ }^{16,17}$ and drug delivery. ${ }^{18,19}$ High internal surface area is one of the foremost attributes of MOFs and has been shown to be highly desirable in many potential applications involving catalysis or storage. (Particularly relevant is the sorption-based storage of technologically important gases at temperatures above their respective critical temperatures. For example, at $T>191 \mathrm{~K}$ methane cannot form methane/methane multilayers; thermodynamically, excess adsorption, therefore, can be achieved only via direct contact between individual methane molecules and the sorbent surface.)

Additionally fueling interest in MOFs is their extraordinary compositional and structural variety (e.g., ca. 10000 experimentally known MOFs versus fewer than 300 zeolites) and the fact that many display permanent porosity, ultralow densities, and well-defined pores and channels. Further, the crystallinity of MOFs allows for their unambiguous structural characterization by X-ray diffraction, greatly simplifying efforts to use computational modeling to predict or explain their unusual or unique physical properties. In this report, we have synthesized and characterized two new MOFs that display the highest experimental Brunauer-Emmett-Teller (BET) surface areas to date $\left(\sim 7000 \mathrm{~m}^{2} / \mathrm{g}\right)$. Additionally, we demonstrate computationally a new surface area ceiling for MOFs $\left(\sim 14600 \mathrm{~m}^{2} / \mathrm{g}\right)$ that substantially exceeds what much of the MOF community perceives to be a theoretical limit $\left(\sim 10500 \mathrm{~m}^{2} / \mathrm{g}\right)$.

One of the first breakthroughs in obtaining MOFs with permanent microporosity came in 1998 from $\mathrm{Li}$ et al., who described a material having a Langmuir surface area of $310 \mathrm{~m}^{2} /$ g. ${ }^{20}$ Striking increases in reported surface areas for MOFs followed for the next several years, with values reaching 3800 $\mathrm{m}^{2} / \mathrm{g}$ in $2005^{21}$ and a remarkable $5200 \mathrm{~m}^{2} / \mathrm{g}$ in 2009. ${ }^{22}$ Among the reported high-area materials were MOF- $5^{23,24}$ (especially in anhydrous form ${ }^{25}$ ), MOF-177, ${ }^{25,26}$ MIL-101, ${ }^{21}$ UMCM-1, ${ }^{27}$ and UMCM-2 ${ }^{22}$ (Table 1). Efforts to achieve even higher surface areas appeared to stall - not primarily because of difficulty in synthesizing new candidate materials, but because of the progressively greater tendency of these materials to collapse upon removal of solvent. Fortunately, a MOF activation method recently introduced by our $\mathrm{lab}^{28,29}$ and based on supercritical carbon dioxide (see below) has enabled difficult-to-activate, large-cavity MOFs to be evacuated without

Received: June 8, 2012

Published: August 20, 2012 
Table 1. BET Surface Areas and Pore Volumes for Highly Porous MOFs

\begin{tabular}{|c|c|c|c|}
\hline MOF & $\begin{array}{l}\text { BET surface area } \\
\qquad\left(\mathrm{m}^{2} \mathrm{~g}^{-1}\right)\end{array}$ & $\begin{array}{l}\text { pore volume } \\
\left(\mathrm{cm}^{3} \mathrm{~g}^{-1}\right)\end{array}$ & ref. \\
\hline MFU-4 L & 2750 & 1.26 & 36 \\
\hline NOTT-102 & 2940 & 1.14 & 37 \\
\hline PCN-61 & 3000 & 1.36 & 38 \\
\hline $\mathrm{Cu}_{24}(\mathrm{TPBTM})_{8}\left(\mathrm{H}_{2} \mathrm{O}\right)_{24}$ & 3160 & 1.27 & 39 \\
\hline SNU-77 & 3670 & 1.52 & 40 \\
\hline NOTT-112 & 3800 & 1.62 & 41 \\
\hline MOF-5 & 3800 & 1.55 & 24 \\
\hline UMCM-1-NH & 3920 & & 42 \\
\hline PCN-66 & 4000 & 1.36 & 38 \\
\hline $\mathrm{Be}_{12}(\mathrm{OH})_{12}(\mathrm{BTB})_{24}$ & 4030 & & 43 \\
\hline UMCM-1 & 4160 & & 27 \\
\hline MIL-101c & 4230 & 2.15 & 21 \\
\hline Bio-MOF-100 & 4300 & 4.30 & 44 \\
\hline MOF-205 & 4460 & 2.16 & 30 \\
\hline MOF-177 & 4750 & 1.59 & 26 \\
\hline DUT-23-Co & 4850 & 2.03 & 45 \\
\hline NOTT-116/PCN-68 & $4660 / 5110$ & 2.17 & 32,46 \\
\hline UMCM-2 & 5200 & 2.32 & 22 \\
\hline NU-100 & 6140 & 2.82 & 31 \\
\hline MOF-210 & 6240 & 3.6 & 30 \\
\hline NU-109E & 7010 & 3.75 & Herein \\
\hline NU-110E & 7140 & 4.40 & Herein \\
\hline
\end{tabular}

framework collapse or channel blockage. Based on this advance, two MOFs with experimentally accessible BET surface areas slightly above $6000 \mathrm{~m}^{2} / \mathrm{g}$ have been reported: MOF-210 30 and NU-100 ${ }^{31}$ (NU = Northwestern University; NU-100 is also known as PCN-610 ${ }^{32}$ ).

\section{RESULTS AND DISCUSSION}

Many researchers believe that the record-high surface areas for NU-100 ${ }^{31}$ and MOF-210" ${ }^{30}$ are "close to the ultimate [experimental] limit for solid materials." ${ }^{33}$ This belief no doubt stems from (a) simulations showing that the upper theoretical limit for MOF surface areas is about $10500 \mathrm{~cm}^{2} / \mathrm{g}$ when linkers are constructed from repeating phenyl groups, ${ }^{25,34}$ and (b) anticipated practical problems, such as poor solubility, low synthetic yields, and cumbersome purification protocols, for candidate linkers featuring very large numbers of phenyl repeat units. We reasoned, however, that both the experimental maximum and the perceived theoretical ceiling could be substantially increased by moving beyond phenyl-only struts to more "area-efficient" acetylene building blocks for MOF linkers. A recent preliminary report from our laboratories provides qualitative support for this notion. ${ }^{35}$

We thus turned our attention to $(3,24)$-paddlewheel connected MOF networks (rht-topology), pioneered by the Eddaoudi group ${ }^{47}$ and significantly further explored by us, ${ }^{31,48}$ Zhou and co-workers ${ }^{32}$ and Schroeder and co-workers. ${ }^{41}$ A key feature of the rht-topology is that catenation (interpenetration or interweaving of multiple frameworks) is mathematically precluded. ${ }^{4,50}$ Capitalizing on this topology, we synthesized two new materials with ultrahigh surface areas, NU-109 and NU-110, from two new hexa-carboxylated linkers. The synthesis and characterization of the hexa-carboxylic-acid forms of the desired linkers $\left(\mathbf{L H}_{\mathbf{6}} \mathbf{- 1}\right.$ and $\mathbf{L H}_{6}-\mathbf{2}$, Figure 1a and $\mathrm{h}$, Schemes S1 and S2) are described in the Supporting Information (SI). Briefly, $\mathbf{L H}_{6}$ species were obtained via

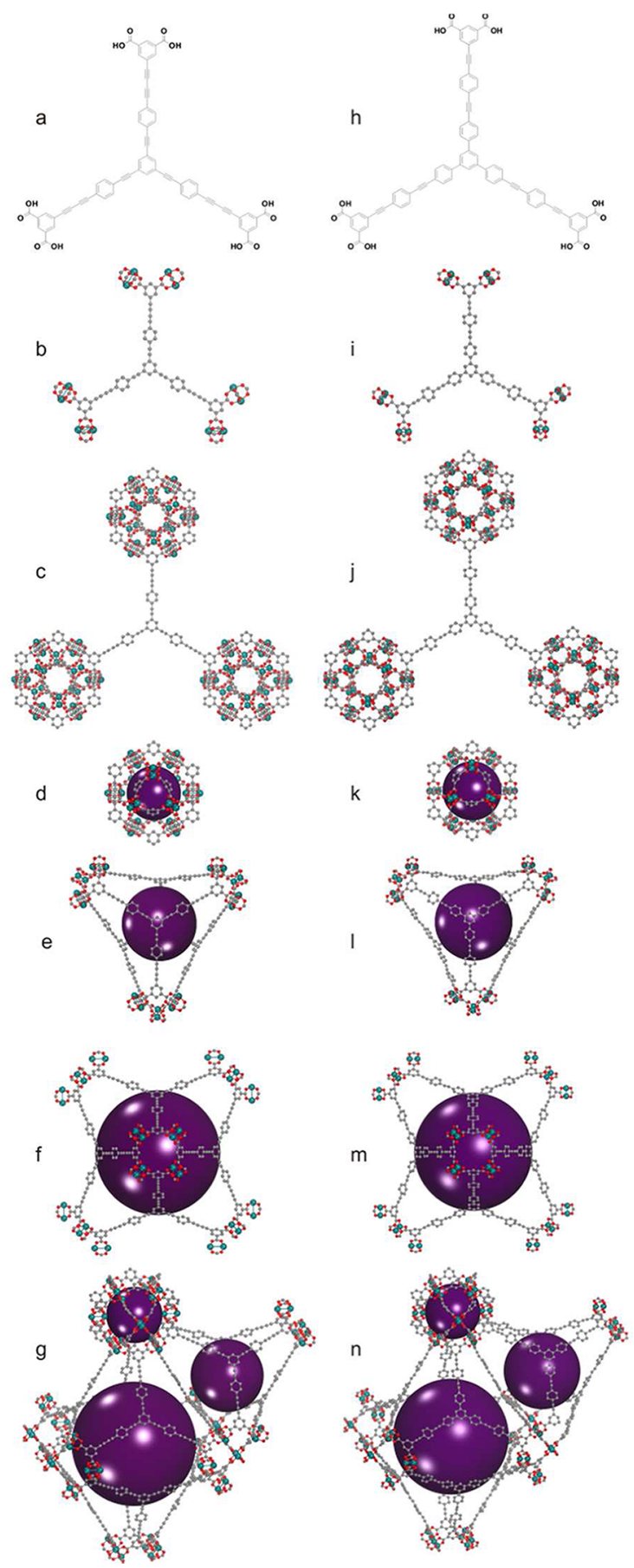

Figure 1. Structural features of NU-109 and NU-110. (a) Schematic drawing of the chemical structure of $\mathbf{L H}_{6}$ for $\mathbf{N U}-109$. (b-g) Representations of the single-crystal X-ray structure of NU-109 showing: $\mathbf{L H}_{6}$ connecting six paddlewheel units (b), cubaoctahedral building blocks (c), and different cages within NU-109 (d-g). (h) Schematic drawing of the chemical structure of $\mathbf{L H}_{6}$ for NU-110. (in) Representations of the single-crystal X-ray structure of NU-110 showing: $\mathbf{L H}_{6}$ connecting six paddlewheel units (i), cubaoctahedral building blocks ( $\mathrm{j})$, and different cages in NU-110 $(\mathrm{k}-\mathrm{n})$. Hydrogens and disordered solvent molecules are omitted for clarity. Carbon $=$ gray; oxygen $=$ red; copper $=$ teal. Purple spheres are included to guide the eye in distinguishing between the three cages.

saponification of the corresponding hexaester precursors, which, in turn, were obtained via Sonagashira coupling of 

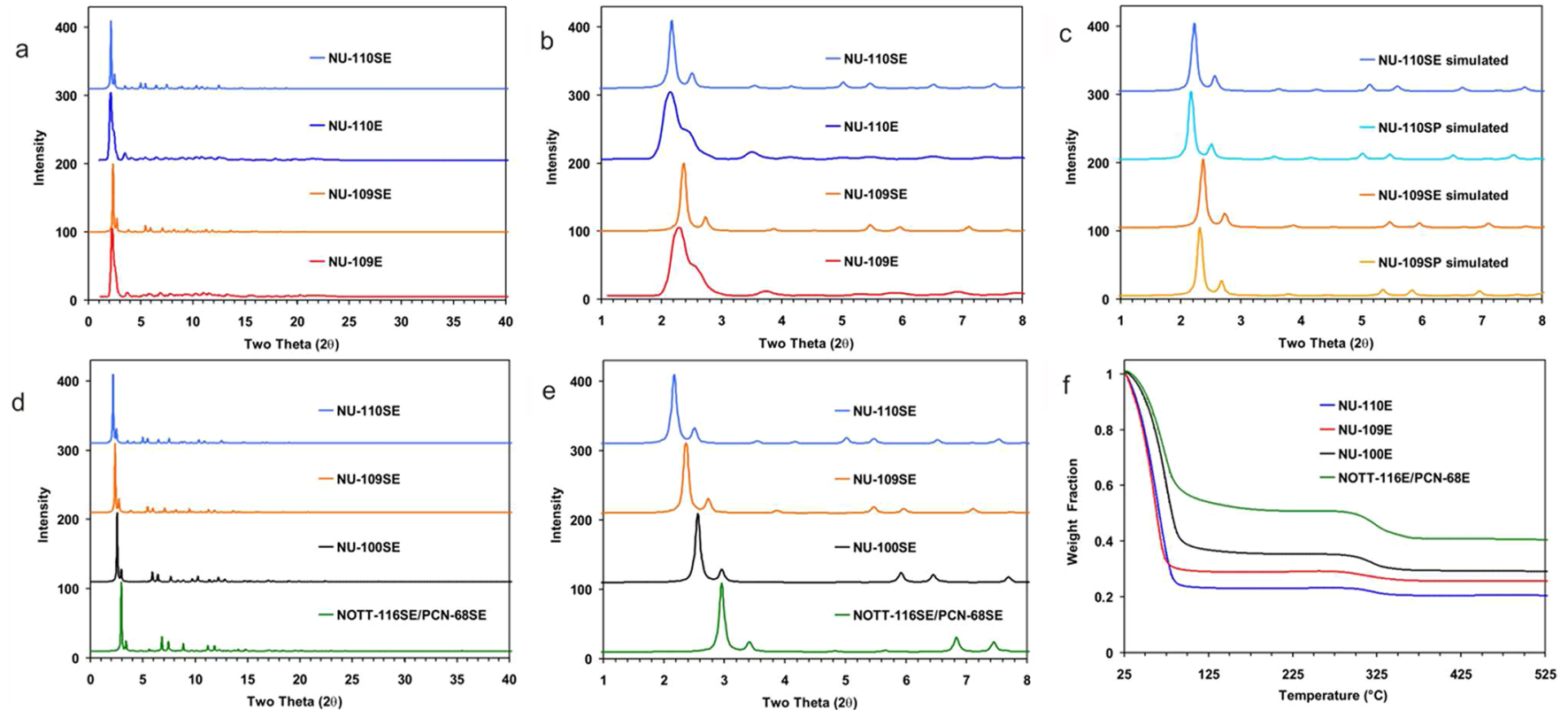

Figure 2. TGA and PXRD profiles. (a-c) PXRD patterns of NU-109 and NU-110. (d-e) PXRD patterns of NU-109, NU-110, NU-100, ${ }^{31}$ and NOTT-116 $/$ PCN-68. $^{32}$ (f) TGA profiles of NU-109, NU-110, NU-100, ${ }^{31}$ and NOTT-116 ${ }^{46} /$ PCN $-68^{32}$

1,3,5-triiodobenzene with the appropriate acetylene-terminated compounds.

Solvothermal reactions of $\mathbf{L H}_{6} \mathbf{- 1}$ or $\mathbf{L H}_{6} \mathbf{- 2}$ and $\mathrm{Cu}-$ $\left(\mathrm{NO}_{3}\right)_{2} \cdot 2.5 \mathrm{H}_{2} \mathrm{O}$ in DMF/EtOH/HCl $(\mathrm{DMF}=$ dimethylformamide) at $75{ }^{\circ} \mathrm{C}$ afforded MOFs having the framework formula $\left[\mathrm{Cu}_{3}\left(\mathrm{~L}^{6-}{ }_{(109)}\right)\left(\mathrm{H}_{2} \mathrm{O}\right)_{3}\right]_{\mathrm{n}}\left(\mathrm{NU}-109 \mathrm{E}, \mathrm{E}=\right.$ Experimental, $\mathbf{L}^{6-}{ }_{(109)}$ $=$ the hexa-anion of $\left.\mathbf{L H}_{\mathbf{6}} \mathbf{- 1}\right)$ or $\left[\mathrm{Cu}_{3}\left(\mathbf{L}^{6-}{ }_{(110)}\right)\left(\mathrm{H}_{2} \mathrm{O}\right)_{3}\right]_{\mathrm{n}}(\mathrm{NU}-$ $110 \mathrm{E}, \mathrm{L}^{6-}{ }_{(110)}=$ the hexa-anion of $\left.\mathrm{LH}_{6}-\mathbf{2}\right)$ after $48 \mathrm{~h}$. X-ray analysis of single crystals of NU-109E and NU-110E revealed noncatenated structures in which the framework nodes consist of $\mathrm{Cu}_{2}{ }_{2}$ units coordinated by the carboxylates of $\mathrm{L}^{6-}$ in a paddlewheel fashion. The axial sites of the $\mathrm{Cu}_{2}{ }_{2}$ units are coordinated by water molecules that were not well resolved in the X-ray analysis (Figures $1 \mathrm{~b}$ and $\mathrm{i}$ ). The experimental structures of NU-109E and NU-110E were found to be in excellent agreement with the predicted structures, NU-109SP (SP = Simulation of the Predicted structure) and NU-110SP (see SI for more details). The predicted and experimental structures of both materials have a cubic space group, $F m \overline{3} m$, with unit-cell dimensions of $a=b=c=65.899 \AA$ (NU-109SP at $0 \mathrm{~K}), 64.528 \AA$ (NU-109E at $100 \mathrm{~K}), 70.330 \AA$ (NU-110SP at $0 \mathrm{~K})$, and $68.706 \AA$ (NU-110E at $297 \mathrm{~K})$. The differences in the unit cells between the experimental and simulated structures are only 1.37 and $1.62 \AA$ for NU-109 and NU110, respectively. The experimental structures were solved, in part, by utilizing the coordinates of the in silico structures predicted by using molecular modeling techniques.

NU-109 and NU-110 share several topological features. Briefly, each $\mathrm{L}^{6-}$ unit contributes to the formation of three cuboctahedron cages (Figures $1 \mathrm{c}$ and $\mathrm{j}$ ). Both contain three types of cages (Figures $1 \mathrm{~g}$ and n, Figure S19) that are fused in ways that provide for continuous channels. Cuboctahedral cage 1 (Figures $1 \mathrm{~d}$ and $\mathrm{k}$ ) is formed from 24 isophthalate groups from $\mathbf{L}^{6-}$ units and 12 pairs of copper ions (i.e., 24 total). The nodes forming triangular windows in cage 1 are shared with cage 2 (Figures 1e and 1), while those forming rectangular windows are shared with cage 3 (Figures if and $\mathrm{m}$ ). Cage 2 (Figures 1e and 1) defines a truncated tetrahedron, and is formed from isophthalate groups from four $\mathbf{L}^{6-}$ linkers and 12 pairs of copper ions (i.e., 24 total). As expected, cage 3 (Figure If and $\mathrm{m}$ ) is describable as a truncated cuboctahedron and is formed by $24 \mathrm{Cu}_{2}{ }^{\mathrm{II}}$ paddlewheel nodes and portions of eight distinct $\mathbf{L}^{6-}$ units.

The phase purity of bulk samples of NU-109 and NU-110 was confirmed via powder X-ray diffraction (PXRD) measurements (Figures 2a and b). Additionally, the simulated PXRD patterns from experimental and predicted structures are in excellent agreement (Figure 2c). This confirms that, apart from minor differences in unit cell dimensions, the predicted structures are identical to the experimentally obtained materials. These differences are tentatively ascribed to the difference between experimental (i.e., X-ray collection) and simulation temperatures. Furthermore, we compared the PXRD patterns of NU-109SE ( $\mathrm{SE}=$ simulated from experimental structure) and NU-110SE to NU-100SE ${ }^{31}$ and NOTT-116 ${ }^{46} / \mathrm{PCN}-68,{ }^{32}$ which likewise share the rht-topology. These patterns (Figures $2 \mathrm{~d}$ and e) show the lowest angle peak progressively shifting to smaller $2 \theta$, which corresponds to an increasing unit cell length and therefore a larger distance between the copper nodes, culminating with NU-110SE. Thermogravimetric analysis (TGA) of NU-109E and NU-110E revealed in both cases a mass loss at about $100{ }^{\circ} \mathrm{C}$, assigned to solvent (DMF), with no further mass loss occurring until $325{ }^{\circ} \mathrm{C}$ (Figure 2f). Both MOFs contain more free solvent than either NU-100E/PCN610 or NOTT-116E/PCN-68E, pointing to the potential for greater permanent porosity.

Regardless of how striking the NU-109E and NU-110E structures may be, for many applications-especially those centering on storage and separation-removal of guest solvent molecules from the pores without significantly diminishing porosity is crucial. Failure to prevent porosity loss will result in significant discrepancies between the surface areas obtained experimentally and those estimated from computational modeling. Since MOFs containing large pores such as NU109 and NU-110 are particularly predisposed to collapse, we employed an unconventional MOF activation strategy recently 
developed by our team ${ }^{28,29}$ and now used by MOF researchers throughout the world (e.g., Kaskel, ${ }^{45}$ Yaghi, $^{30,51} \mathrm{Hong}^{52}$ and others) to activate them. The activation takes advantage of supercritical carbon dioxide (SCD) processing, which was performed with a Tousimis Samdri PVT-30 critical point dryer. Prior to drying, DMF/EtOH-solvated MOF samples were soaked in $100 \%$ ethanol, replacing the soaking solution every day for 3 days. The ethanol-containing samples were placed inside the dryer and the ethanol was exchanged with $\mathrm{CO}_{2}$ (liq.) over a period of $10 \mathrm{~h}$. The temperature was then raised and $\mathrm{CO}_{2}$ was vented under supercritical conditions where capillary forces and solvent surface-tension are inherently absent (see SI for more details).

The porosities of SCD-activated NU-109 and NU-110 were examined via nitrogen adsorption at $77 \mathrm{~K} . \mathrm{N}_{2}$ isotherms showed extraordinarily high limiting uptakes of 2480 and 2845 $\mathrm{cm}^{3} / \mathrm{g}$ for NU-109E and NU-110E, respectively (Figure 3).

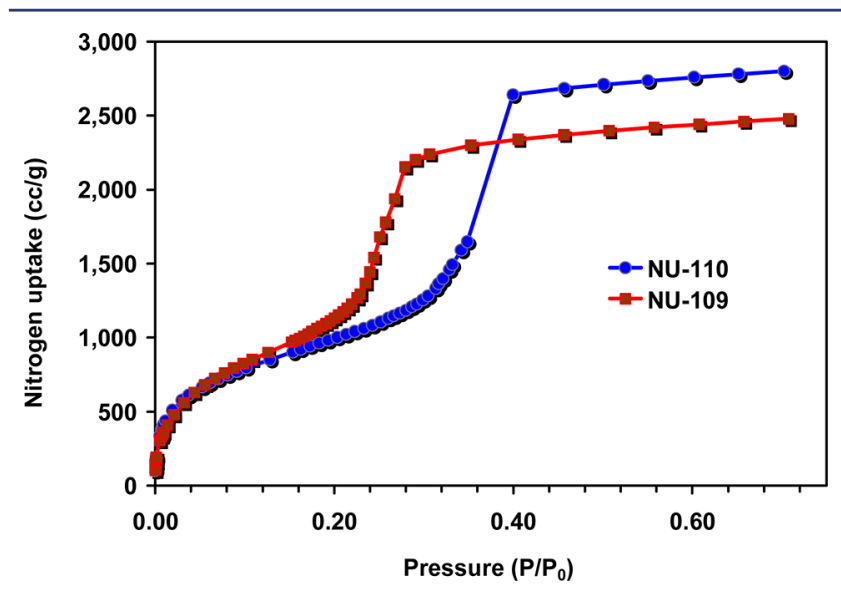

Figure 3. Sorption data for NU-109E and NU-110E. Experimental nitrogen isotherms for NU-109E (red squares) and NU-110E (blue circles).

The experimental BET surface areas of activated NU-109E and NU-110E were found to be 7010 and $7140 \mathrm{~m}^{2} / \mathrm{g}$, in excellent agreement with the fitted (in silico) BET surface areas for NU109SE $\left(6950 \mathrm{~m}^{2} / \mathrm{g}\right)$ and NU-110SE $\left(7400 \mathrm{~m}^{2} / \mathrm{g}\right)$ and with the simulated BET surface area for NU-109SP $\left(7560 \mathrm{~m}^{2} / \mathrm{g}\right)$ and NU-110SP $\left(7800 \mathrm{~m}^{2} / \mathrm{g}\right)$ (Table 2). The deviation in surface areas between the SE and SP materials reflect the small, but finite, differences in dimensions of the experimental versus calculated unit cells. Nonetheless, these surface areas are the highest for any porous materials reported to date. Moreover, the total pore volumes of NU-109E and NU-110E are 3.75 and $4.40 \mathrm{~cm}^{3} / \mathrm{g}$, which are substantially larger than any other high-

Table 2. Experimental and Simulated Surface Areas and Pore Volumes for NU-109, NU-110, NU-109SP, and NU-110SP ${ }^{a}$

\begin{tabular}{|lcc|}
\hline MOF & BET surface area $\left(\mathrm{m}^{2} \mathrm{~g}^{-1}\right)$ & pore volume $\left(\mathrm{cm}^{3} \mathrm{~g}^{-1}\right)$ \\
NU-109SP & 7560 & 4.12 \\
NU-109SE & 6950 & 3.90 \\
NU-109E & $7010 \pm 80$ & 3.75 \\
NU-110SP & 7800 & 4.44 \\
NU-110SE & 7400 & 4.18 \\
NU-110E & 7140 & 4.40
\end{tabular}

${ }^{a} \mathrm{SP}=$ simulated from predicted structure; $\mathrm{SE}=$ simulated from experimental structure; $\mathrm{E}=$ experimental results. pore-volume MOFs (see Table 1). Finally, the observed void volumes of ca. 93\% (for each) exceed those for any other solvent-evacuated MOF material described to date. It is worth noting that the nitrogen isotherms shown in Figure 3 are typeIV rather than type-I, reflecting the fact that both NU-109 and NU-110 contain multiple types (sizes) of pores. The simulated isotherms show three distinct regions, while the experimental data do not resolve these as clearly. However, the simulated and experimental pore size distributions are in excellent agreement as shown in Figures S30 and S32 (SI). Additionally, PXRD patterns for as-synthesized, activated, and resolvated NU-109 and NU-100 show no evidence for structural changes during activation and porosity measurements (Figures S34 and S35).

While the BET surface areas of the new MOFs are large (nearly $70 \%$ of the theoretical maximum for materials with benzene-derived linkers), can higher surface area materials be experimentally obtained? Attempts have been made previously to calculate the highest possible surface area for a porous material. Chae at al. ${ }^{25}$ described a useful conceptual basis for a strategy to achieve high-surface-area ordered materials. By progressively excising smaller fragments from an infinite graphene sheet and calculating Connolly ${ }^{53}$ surface areas of the remaining framework, they found that exposing all latent edges to give isolated six-membered rings would yield a surface area of $7745 \mathrm{~m}^{2} / \mathrm{g}$. The exposed six-membered rings were essentially benzene molecules without hydrogens, whose inclusion would have given an even higher surface area. By putting this strategy into practice, they synthesized MOF-177 from $\mathrm{Zn}_{4} \mathrm{O}$ clusters and 1,3,5-benzenetribenzoate (BTB) organic linkers, which showed a record-breaking surface area at that time $\left(4750 \mathrm{~cm}^{2} / \mathrm{g}\right)$. (Subsequently, it was realized that for sorption applications, molecule-accessible surface areas are physically more meaningful than Connolly surface areas. ${ }^{54}$ Additionally, Snurr and co-workers showed that, subject to well-defined "consistency criteria", experimental BET surface areas for fully evacuated MOFs (but not Langmuir or Connolly surface areas) correspond closely to molecule-accessible surface areas. $^{54}$ )

In a related approach, Schnobrich et al. ${ }^{34}$ constructed a series of structures (in silico) by incrementally adding benzenes to the linker of MOF-5 (1,4-terephthalic acid). This study revealed that a MOF-5 analogue with an infinite number of benzenes in its linker would give an $\mathrm{N}_{2}$-accessible surface area of $10436 \mathrm{~m}^{2} /$ $\mathrm{g}$, which is very close to the maximum attainable surface area $\left(10577 \mathrm{~m}^{2} / \mathrm{g}\right)$ for structures derived from benzene rings regardless of their topology. These studies have, until now, largely defined surface-area targets for MOF materials for both experimental and theoretical investigations, and the use of benzene chains of different forms and lengths has become a common way of synthesizing materials with high surface areas.

Here we propose and demonstrate that there are routes to attaining MOFs with even higher surface areas. The basis of one of these routes relies on further exposing the edges of a sixmembered carbon ring by dividing it into three separate but chemically linked pieces, where each consists of two carbon atoms linked by a triple bond. These pieces are roughly equivalent to acetylenes, but with carbon-carbon single bonds to neighboring pieces replacing terminal hydrogen atoms. Employing three linked acetylenes in place of a single benzene ring in a material should result in a significantly higher molecule-accessible surface area, since larger numbers of exposed edges (i.e., adsorption sites) are presented. ${ }^{54} \mathrm{We}$ hypothesized that stepwise addition of acetylenes to the linker 
of a MOF would yield, substantially higher gravimetric surface than would the stepwise addition of benzene units (for comparisons at the same unit cell size).

To test the hypothesis, we constructed three series of hypothetical MOFs based on (3,24)-paddlewheel connected networks. (Recall that these networks, in contrast to that for, say, MOF-5, cannot form interpenetrated structures-an important practical consideration, as catenation can otherwise present a major experimental obstacle to obtaining high surface area materials. For example, a family of highly catenated (ca. 12-fold) terpyridine-based coordination polymers recently described by our laboratories, exhibits surface areas of a few to several hundred $\mathrm{m}^{2} / \mathrm{g} ;{ }^{55}$ however, the polymers would be expected to yield surface areas higher than $6400 \mathrm{~m}^{2} / \mathrm{g}$ if they could ever be prepared in single-network form.) The desired hypothetical structures were constructed by incrementally adding (a) phenyl, (b) phenylethynyl, or (c) ethynyl groups to the $\mathrm{Cu}_{2}{ }^{\mathrm{II}}$-paddlewheel clusters until their unit-cell edge lengths reached at least $300 \AA$ (Figure 4). For each series, we
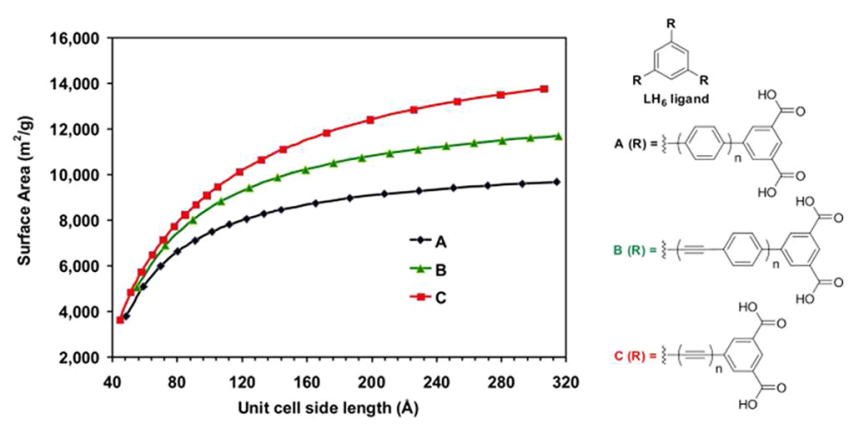

Figure 4. Estimated accessible surface areas of MOFs with rhttopology constructed by $\mathrm{LH}_{6}$ ligands consisting of linkers $\mathrm{A}, \mathrm{B}$, and $\mathrm{C}$, where the center benzene of the ligand was extended by addition of increasing number $(n)$ of phenyl, phenylethynyl, and ethynyl moieties, respectively. For the longest unit cell edge lengths $(\sim 310 \AA), n$ is 26 , 15 , and 40 for $\mathbf{A}, \mathbf{B}$, and $\mathbf{C}$, respectively.

then calculated accessible surface areas and plotted them against the unit-cell lengths; as anticipated, the areas become progressively larger as the cell lengths increases. Upper limit surface areas were determined by implementing a high-quality fitting that entailed the use of a five-parameter "exponential rise to max" equation (see SI for details). When only phenyl units were used in the linkers (case a), the upper limit for the gravimetric surface area was found to be $9950 \mathrm{~m}^{2} / \mathrm{g}$, which is only slightly lower than the theoretical limit reported for MOFs derived from benzene-containing struts. ${ }^{25,34}$ When phenylethynyl groups were used (case b), we found that the upper limit of the gravimetric surface area increased to a value of $12250 \mathrm{~m}^{2} / \mathrm{g}$. Finally and most excitingly, the use of only ethynyl units in the linker extensions (case c) resulted in an upper limit of $14600 \mathrm{~m}^{2} / \mathrm{g}$.

The computational modeling results clearly show that the strategy of using progressively more acetylenes in the organic linkers of MOFs, whether alone or with other molecular subunits, has the potential of creating ordered structures with surface areas substantially higher than any previously envisioned for metal-organic framework materials. Importantly, it seems reasonable to conclude that even the recordhigh surface area of $7140 \mathrm{~m}^{2} / \mathrm{g}$ for NU-110 does not define the practical experimental upper limit for surface areas of porous materials, as it corresponds to only about $49 \%$ of the theoretical upper limit for MOFs featuring acetylene-rich linkers. Indeed, it is conceivable that other linker motifs-for example, ones based on extended polyenes, or on connecting-atoms that are lighter than carbon-could yield even higher computational ceilings for surface areas.

\section{CONCLUSIONS}

The utility of NU-109 and NU-110 as new benchmark, ultrahigh surface area materials has been demonstrated synthetically and corroborated computationally. We also have shown that the theoretical upper limit for MOF surface areas is $14600 \mathrm{~m}^{2} / \mathrm{g}$, if not higher.

\section{ASSOCIATED CONTENT}

\section{Supporting Information}

Synthesis of $\mathbf{L H}_{6}$ ligand, NU-109E and NU-110E MOFs; X-ray crystallography analysis, activation, $\mathrm{N}_{2}$ gas adsorption, pore size distribution, PXRD, and experimental and simulated BET surface area analyses of MOFs NU-109E and NU-110E; details of molecular simulations and geometric surface area calculation of $\mathbf{A}, \mathbf{B}$, and $\mathbf{C}$ MOF series. This material is available free of charge via the Internet at http://pubs.acs.org.

\section{AUTHOR INFORMATION}

\section{Corresponding Author}

o-farha@northwestern.edu; a.yazaydin@surrey.ac.uk; j-hupp@ northwestern.edu

\section{Author Contributions}

† These authors contributed equally.

\section{Notes}

The authors declare no competing financial interest.

\section{ACKNOWLEDGMENTS}

J.T.H., S.T.N., and R.Q.S. gratefully acknowledge the U.S. Dept. of Energy's Office of Energy Efficiency and Renewable Energy for primary financial support. I.E. is supported by NSF grant \# EEC-0647560 administered through the Northwestern NSEC, which also provides additional general support on MOF design and synthesis. A.Ö.Y. thanks the European Commission Marie Curie International Reintegration for financial support. S.T.N. acknowledges additional financial support from the AFOSR. The Cambridge Crystallographic Data Centre deposition numbers for NU-109 and NU-110 are CCDC 856012 and 856013 , respectively.

\section{REFERENCES}

(1) O’Keeffe, M.; Peskov, M. A.; Ramsden, S. J.; Yaghi, O. M. Acc. Chem. Res. 2008, 41, 1782.

(2) Férey, G. Chem. Soc. Rev. 2008, 37, 191.

(3) Horike, S.; Shimomura, S.; Kitagawa, S. Nat. Chem. 2009, 1, 695.

(4) Murray, L. J.; Dincă, M.; Long, J. R. Chem. Soc. Rev. 2009, 38, 1294.

(5) Hu, Y. H.; Zhang, L. Adv. Mater. 2010, 22, E117.

(6) Sculley, J.; Yuan, D.; Zhou, H.-C. Energy Environ. Sci. 2011, 4, 2721.

(7) Li, J.-R; Kuppler, R. J.; Zhou, H.-C. Chem. Soc. Rev. 2009, 38, 1477.

(8) An, J.; Geib, S. J.; Rosi, N. L. J. Am. Chem. Soc. 2010, 132, 38.

(9) Britt, D.; Furukawa, H.; Wang, B.; Glover, T. G.; Yaghi, O. M. Proc. Natl. Acad. Sci. U.S.A. 2009, 106, 20637.

(10) Bae, Y.-S.; Spokoyny, A. M.; Farha, O. K.; Snurr, R. Q.; Hupp, J. T.; Mirkin, C. A. Chem. Commun. 2010, 46, 3478. 
(11) Allendorf, M. D.; Bauer, C. A.; Bhakta, R. K.; Houk, R. J. T. Chem. Soc. Rev. 2009, 38, 1330.

(12) Ma, L.; Abney, C.; Lin, W. Chem. Soc. Rev. 2009, 38, 1248.

(13) Lee, J.; Farha, O. K.; Roberts, J.; Scheidt, K. A.; Nguyen, S. T.; Hupp, J. T. Chem. Soc. Rev. 2009, 38, 1450.

(14) Farha, O. K.; Shultz, A. M.; Sarjeant, A. A.; Nguyen, S. T.;

Hupp, J. T. J. Am. Chem. Soc. 2011, 133, 5652.

(15) An, J.; Rosi, N. L. J. Am. Chem. Soc. 2010, 132, 5578

(16) Lee, C. Y.; Farha, O. K.; Hong, B. J.; Sarjeant, A. A.; Nguyen, S.

T.; Hupp, J. T. J. Am. Chem. Soc. 2011, 133, 15858.

(17) Kent, C. A.; Mehl, B. P.; Ma, L.; Papanikolas, J. M.; Meyer, T. J.; Lin, W. J. Am. Chem. Soc. 2010, 132, 12767.

(18) Horcajada, P.; Serre, C.; Vallet-Regí, M.; Sebban, M.; Taulelle,

F.; Férey, G. Angew. Chem., Int. Ed. 2006, 45, 5974.

(19) Rocca, J. D.; Liu, D.; Lin, W. Acc. Chem. Res. 2011, 44, 957.

(20) Li, H.; Eddaoudi, M.; Groy, T. L.; Yaghi, O. M. J. Am. Chem. Soc. 1998, 120, 8571.

(21) Férey, G.; Mellot-Draznieks, C.; Serre, C.; Millange, F.; Dutour, J.; Surblé, S.; Margiolaki, I. Science 2005, 309, 2040.

(22) Koh, K.; Wong-Foy, A. G.; Matzger, A. J. J. Am. Chem. Soc. 2009, 131, 4184.

(23) Li, H.; Eddaoudi, M.; O’Keeffe, M.; Yaghi, O. M. Nature 1999, 402, 276.

(24) Kaye, S. S.; Dailly, A.; Yaghi, O. M.; Long, J. R. J. Am. Chem. Soc. 2007, 129, 14176

(25) Chae, H. K.; Siberio-Pérez, D. Y.; Kim, J.; Go, Y.; Eddaoudi, M.; Matzger, A. J.; O’Keeffe, M.; Yaghi, O. M. Nature 2004, 427, 523.

(26) Furukawa, H.; Miller, M. A.; Yaghi, O. M. J. Mater. Chem. 2007, 17, 3197.

(27) Koh, K.; Wong-Foy, A. G.; Matzger, A. J. Angew. Chem., Int. Ed. 2008, 47, 677.

(28) Nelson, A. P.; Farha, O. K.; Mulfort, K. L.; Hupp, J. T. J. Am. Chem. Soc. 2008, 131, 458.

(29) Farha, O. K.; Hupp, J. T. Acc. Chem. Res. 2010, 43, 1166.

(30) Furukawa, H.; Ko, N.; Go, Y. B.; Aratani, N.; Choi, S. B.; Choi,

E.; Yazaydın, A. Ö.; Snurr, R. Q.; O’Keeffe, M.; Kim, J.; Yaghi, O. M. Science 2010, 329, 424.

(31) Farha, O. K.; Yazaydın, A. Ö.; Eryazici, I.; Malliakas, C. D.; Hauser, B. G.; Kanatzidis, M. G.; Nguyen, S. T.; Snurr, R. Q.; Hupp, J. T. Nat. Chem. 2010, 2, 944.

(32) Yuan, D.; Zhao, D.; Sun, D.; Zhou, H.-C. Angew. Chem., Int. Ed. 2010, 49, 5357.

(33) Liu, J.; Thallapally, P. K.; McGrail, B. P.; Brown, D. R.; Liu, J. Chem. Soc. Rev. 2012.

(34) Schnobrich, J. K.; Koh, K.; Sura, K. N.; Matzger, A. J. Langmuir 2010, 26, 5808.

(35) Farha, O. K.; Wilmer, C. E.; Eryazici, I.; Hauser, B. G.; Parilla, P. A.; O’Neill, K.; Sarjeant, A. A.; Nguyen, S. T.; Snurr, R. Q.; Hupp, J. T. J. Am. Chem. Soc. 2012, 134, 9860.

(36) Denysenko, D.; Grzywa, M.; Tonigold, M.; Streppel, B.; Krkljus, I.; Hirscher, M.; Mugnaioli, E.; Kolb, U.; Hanss, J.; Volkmer, D. Chem.-Eur. J. 2011, 17, 1837.

(37) Lin, X.; Telepeni, I.; Blake, A. J.; Dailly, A.; Brown, C. M.; Simmons, J. M.; Zoppi, M.; Walker, G. S.; Thomas, K. M.; Mays, T. J.; Hubberstey, P.; Champness, N. R.; Schröder, M. J. Am. Chem. Soc. 2009, 131, 2159.

(38) Zhao, D.; Yuan, D.; Sun, D.; Zhou, H.-C. J. Am. Chem. Soc. 2009, 131, 9186.

(39) Zheng, B.; Bai, J.; Duan, J.; Wojtas, L.; Zaworotko, M. J. J. Am. Chem. Soc. 2011, 133, 748.

(40) Park, H. J.; Lim, D.-W.; Yang, W. S.; Oh, T.-R.; Suh, M. P. Chem.-Eur. J. 2011, 17, 7251.

(41) Yan, Y.; Lin, X.; Yang, S.; Blake, A. J.; Dailly, A.; Champness, N. R.; Hubberstey, P.; Schröder, M. Chem. Commun. 2009, 1025.

(42) Wang, Z.; Tanabe, K. K.; Cohen, S. M. Chem.-Eur. J. 2010, 16, 212.

(43) Sumida, K.; Hill, M. R.; Horike, S.; Dailly, A.; Long, J. R. J. Am. Chem. Soc. 2009, 131, 15120.
(44) An, J.; Farha, O. K.; Hupp, J. T.; Pohl, E.; Yeh, J. I.; Rosi, N. L. Nat. Commun. 2012, 3, 604.

(45) Klein, N.; Senkovska, I.; Baburin, I. A.; Grünker, R.; Stoeck, U.; Schlichtenmayer, M.; Streppel, B.; Mueller, U.; Leoni, S.; Hirscher, M.; Kaskel, S. Chem.-Eur. J. 2011, 17, 13007.

(46) Yan, Y.; Telepeni, I.; Yang, S.; Lin, X.; Kockelmann, W.; Dailly, A.; Blake, A. J.; Lewis, W.; Walker, G. S.; Allan, D. R.; Barnett, S. A.; Champness, N. R.; Schröder, M. J. Am. Chem. Soc. 2010, 132, 4092.

(47) Nouar, F.; Eubank, J. F.; Bousquet, T.; Wojtas, L.; Zaworotko, M. J.; Eddaoudi, M. J. Am. Chem. Soc. 2008, 130, 1833.

(48) Eryazici, I.; Farha, O. K.; Hauser, B. G.; Yazaydın, A. Ö.; Sarjeant, A. A.; Nguyen, S. T.; Hupp, J. T. Cryst. Growth Des. 2012, 12, 1075.

(49) Delgado-Friedrichs, O.; O’Keeffe, M. Acta Crystallogr., Sect. A 2007, 63, 344.

(50) Reticular Chemistry Structure Resource (RCSR) website, http://rcsr.anu.edu.au/.

(51) Valente, C.; Choi, E.; Belowich, M. E.; Doonan, C. J.; Li, Q.; Gasa, T. B.; Botros, Y. Y.; Yaghi, O. M.; Stoddart, J. F. Chem. Commun. 2010, 46, 4911.

(52) Han, D.; Jiang, F.-L.; Wu, M.-Y.; Chen, L.; Chen, Q.-H.; Hong, M.-C. Chem. Commun. 2011, 47, 9861.

(53) Connolly, M. L. Science 1983, 221, 709.

(54) Düren, T.; Millange, F.; Férey, G.; Walton, K. S.; Snurr, R. Q. J. Phys. Chem. C 2007, 111, 15350.

(55) Eryazici, I.; Farha, O. K.; Compton, O. C.; Stern, C.; Hupp, J. T.; Nguyen, S. T. Dalton Trans. 2011, 40, 9189. 